\title{
Knowledge Management Approaches for Customer Care Effectiveness
}

\author{
A. V. Murali \\ Software consultant
}

\begin{abstract}
Knowledge management is a critical component of every customer care process. Any organization that aspires to achieve a high level of customer satisfaction must focus on empowering its customer care representatives with sufficient knowledge of their products and services and make it available at the right time. The focus must be on the knowledge base, its organization and its availability within an acceptable time for retrieval. The knowledge base should be current and it should be accessible with minimum effort. This paper discusses the essential elements of knowledge management in the context of customer care for the telecom industry, with the objective of making retrieval of information quick and easy for customer care representatives. The ideas can be easily extended to other business domains.
\end{abstract}

Keywords: Customer care, Knowledge management, Indexing, Knowledge base, Customer experience, Customer relationship.

\section{Introduction}

Knowledge management $(\mathrm{KM})$ is the process of capturing, developing, sharing, and effectively using organizational knowledge [1]. KM facilitates effective gathering, processing and dissemination of knowledge. KM emerged as a scientific discipline in the early 1990s [2].

One of the key elements for success of a customer care organization is the way knowledge is managed and made available to their customer care representatives (CSR). A customer who calls up customer care seeking information on a new product model would expect the CSR to have sufficient knowledge of the model vis-à-vis other models. Apart from the soft skills that a CSR is expected to possess, her knowledge about the products and services of the organization that she serves are crucial. If a CSR does not have enough information or takes a long time to retrieve a piece of information, the customer might feel frustrated and hang-up the call; and it is a missed opportunity for the organization. With the instant availability of social media, a customer who is frustrated or angry due to a poor level of service is likely to create more damage to the organization. Customer experience is the key to maintain healthy customer relationship.

Knowledge in organizations is available in several forms. It is present as product pamphlets, sales manuals, technical manuals, process manuals and product notes. Knowledge may be available as a Word document or a PDF or an Excel file or a PowerPoint document. Some of them may be available on the intranet in file form or in a database server. Whatever be the form or location, the knowledge should be made available to the CSR in an easily readable form at the critical moment when a customer is seeking information from the CSR and waiting for her response. An increase in customer satisfaction means an increase in customer loyalty and retention. CSRs who are better equipped with knowledge management $(\mathrm{KM})$ tools have lower handling time in resolving customer queries and complaints and have a higher first call resolution rate.

\section{Literature Survey}

The success of a knowledge management initiative depends not only on the knowledge base per se but also on its delivery. This is especially true for organizations with complex product portfolios. CSRs who are the prime users in a customer care organization are expected to deliver consistent information to customers in a timely manner. Failure to do so would result in redundant service efforts. It requires centralization of control and a matured knowledge management process. Several books have been written on the theory and practice of KM [3], on how to design the KM strategy [4] and on how to implement KM in an organization [5]. Some authors have emphasized the importance of integrating KM with customer relationship management (CRM) [6], [7]. Several dozens of knowledge management solutions are available in the market today. They vary in their richness of features, their ability to organize information, their interoperability and extensibility, their end-to-end process focus and performance. Many of them support the key phases of knowledge management process, namely knowledge acquisition, processing, organization, dissemination, update and archival. Tyndale [8] discusses the taxonomy of KM tools, which may be of help in evaluating and selecting the right $\mathrm{KM}$ tool for an organization.

\section{The Objective}

Knowledge management forms a key strategic area for the business and helps in overall productivity of all its employees. In this paper we focus on the KM integration requirements, $\mathrm{KM}$ portal design and $\mathrm{KM}$ processes (collectively referred to here as KM design) that can reduce the time taken by CSR to search information when the customer is on call and thus become the enabler for high level of customer satisfaction. Specifically, the GUI for user navigation, the workflow design and the system integrations are our prime focus areas for KM design. The paper starts with a brief discussion on the broad approach to be taken for $\mathrm{KM}$ implementation and lists down the business requirements for a KM portal. Subsequently, the KM Portal integrations, 


\section{International Journal of Science and Research (IJSR) \\ ISSN (Online): 2319-7064}

Index Copernicus Value (2013): 6.14 | Impact Factor (2015): 6.391

the KM Navigation and the KM Workflow Management are discussed, keeping in mind the CSR's need for quick access to information. We consider the telecom industry for developing our design. The same ideas can be extended to other business domains as well.

\section{The Approach}

Before we discuss the KM requirements and the KM design from the customer care's perspective, we shall briefly highlight the prerequisites for a successful KM initiative.

\subsection{Prerequisites}

The most important prerequisite for the success of a KM initiative is management buy-in and commitment. Management ought to be convinced about the need for KM and should be clear about their expectations from the KM rollout.

Having reached a consensus on its importance and their expectations, a cross-functional KM taskforce that "is responsible for rolling out the KM system shall be formed. Its organization, its constitution and the roles and responsibilities of various stakeholders shall be identified before undertaking the journey further. The taskforce shall identify a detailed list of requirements and develop a detailed plan for the KM rollout. Having developed a plan, the team shall ensure that the resource requirements are met and move on to the execution phase. It is needless to say that a person from customer care would be one of the stakeholders who would be the single point of contact for all the customer care requirements and who will be responsible for providing the inputs and spelling out the requirements to other stakeholders including systems designers, process designers, product teams and technology teams. The teams will work together to develop the system, ensure readiness of all technology, process and people resources and bring out the initial version of the KM system in a phased manner eventually leading to a complete rollout. In the meantime, the process for day-to-day management of knowledge after the rollout, shall be designed. It includes knowledge acquisition, processing, creation, dissemination, update and archival.

With this brief discussion on the prerequisites, we will now move on to the KM requirements from the customer care's perspective. We have considered telecom industry for our discussion. The ideas can be extended to other domains as well, taking into account the nature of the products and services.

\subsection{KM requirements}

The CSR needs instant access to information when a customer contacts her. Customer information as well as the information that the customer seeks are required in the desired form within an acceptable time duration, with minimal effort on the part of the CSR. We assume that CSRs would use either a desktop or a laptop as a primary client platform and would require a KM portal for access to information. For CSRs who may have to use tablets and smartphones as alternative platforms, an Android or iOS app may be built that includes as many features of the KM portal as possible.

While the customer data is typically stored in structured form in databases, the information that the customer seeks may be unstructured or partially structured and is often available in text documents.

While some of the information that the CSR accesses is relatively static and does not change with time, there are some that change frequently. The CSR may have to be alerted whenever such changes occur. The information that is displayed on the screen shall be organized in such a way that it does not place much strain on the CSR to search, read, understand and explain to the customer.

\subsection{Information Structure}

Before we discuss the GUI design consideration, we shall list down the types of information that a CSR will have to deal with. This information can fall into one of the following 3 categories:

\section{Structured and semi-structured: \\ 1. Relational \\ 2. Hierarchical \\ 3. Graph or Network structure \\ 4. Rules \\ 5. XML \\ 6. JSON (attribute-value pairs)}

Unstructured:

7. Information embedded within text documents, video and audio files

The raw information have to be processed, put together and presented in such a way that the CSRs can quickly understand them while attending to a customer's call.

\subsection{Information Categories}

The categories of information that may be accessed by CSR who works for a telecom service provider are listed below.

1. Product master data

2. Product transactional data

3. Processes, procedures and their versions

4. Basic services master data

5. Basic services transactional data

6. Value added services (VAS) data

7. VAS transactional data

8. Organizational entities: Points of contact, roles and responsibilities and other attributes, offices, factories and networks

9. Supplier (vendor), Business partner information

10. Service center information

11. Organizational policies and business rules

12. Government regulations (current and historical)

13. Industry standards

14. Events triggering alerts

15. Market and competitor information

16. Sales information

\section{Volume 5 Issue 5, May 2016}




\section{International Journal of Science and Research (IJSR) \\ ISSN (Online): 2319-7064}

Index Copernicus Value (2013): 6.14 | Impact Factor (2015): 6.391

17. Manuals on Products, Services, Technical specifications and Processes

18. Audio and Video recordings

19. Plans, offers and vouchers

20. Payments related information: bills, bill status, balance, due date and validity

21. Customer account and customer eligibility information

22. Customer transactions data

23. Geographical information

24. Network design information

25. Network status information

\subsection{Derived Information}

The above list shows the fundamental elements of $\mathrm{KM}$ for telecom industry. Further information can be derived by identifying the relevant links between them. This is an elaborate process that requires meticulous planning. For example, a specific model of a phone may be available with only one business partner. Likewise, a particular service or a plan may be available in select cities. CSR will need access to information that is relational in nature. All these relations will have to be identified before planning a GUI for KM Portal. A CSR will need to access different kinds of related information within a short time, without having to navigate through too many links on the portal.

\subsection{KM Portal Integration}

We have seen information of different categories and their relationships. They are managed and made available by different systems. Some of them are CRM, DSS, BSS, OSS, Office productivity tools, business partner systems, Email communications and other proprietary tools. Some may come in the form of alerts and automatic feeds. With information available from several data sources, they should be organized on the screen in such a way that the CSR does not have to switch between different tools too often while engaging in a conversation with the customer. KM Portal needs to be integrated with other systems in a judicious manner. All customer scenarios ought to be considered while planning for integration of various systems with the $\mathrm{KM}$ portal for presenting the information to the CSR in the most desired manner. The choice of integration methodology would depend on the capabilities of the systems that need to be integrated with the KM Portal.

Client side integration among different software clients running on the CSR's desktop ought to be implemented, for reducing copy paste kind of operations from one application to another.

The information selected by the CSR in the KM portal should be automatically made available in other clients and vice versa. For example, when a customer calls up and reaches a CSR, his information pops up in the CRM. This information may contain his current data plan. If he wants to know about different plans available for him, a click from the CRM should take him to the relevant page in the KM portal where different plans for which he is eligible are displayed. Now if he wants to subscribe to one of them, a mouse click on the KM Portal should take the CSR directly to the CRM where the data gets auto populated. All that the CSR has to do is to just confirm the selection. Without this type of integration, the CSR will have to navigate through several links in both the systems before completing the transaction.

When the customer calls up customer care, he is first greeted by the interactive voice response (IVR) system. The customer might navigate through the IVR menus before reaching the CSR. If the KM portal is integrated with IVR then the KM portal can display additional information that is related to what he had listened to in the IVR. This will again save a few mouse clicks for the CSR and enable the CSR to ask questions that are relevant to the customer.

Integration of KM portal with other systems such as DSS, OSS and other third party system are also possible, whereby the information sharing can happen between the KM portal and the respective system.

\subsection{KM Portal Navigation}

The design of the KM portal is a major deciding factor when it comes to ease of access of information. A poorly designed portal will make the CSR use too many mouse clicks on most of the calls.

Among the information that were listed earlier, some are accessed more frequently than others and this frequently accessed information may change with time. The KM tool should be able to display the top few (say, top 10) frequently accessed information to the CSR, so that her search time can be reduced when on call. This requires a periodic update of top few call reasons which can be done automatically without human intervention.

The KM tool should keep track of the sequence of mouse click events for every call so that it can be analyzed in detail. Data mining tools allow extensive analysis of such data so that the KM portal can be reorganized for reducing the average mouse clicks required per call.

While most of the information can be organized in the portal in a hierarchical manner, clicking through the hierarchy from the top level to the required level of detail for every call can be tedious and time-consuming. To avoid this, quick access tools should be made available to the CSR. For example, a search box that allows the CSR to type only a few characters for the required information would go a long way in reducing the effort considerably. The system would display all relevant choices to the CSR and the CSR will have to select one from the list. On selecting it, the system should display the tree hierarchy leading to that information along with the detailed information on that topic. This would require indexing of the pages and maintaining of the information as to where exactly they are available within the documents. This can be further augmented with approximate search feature like edit distance based search, whereby the CSR need not worry about knowing the exact spelling for the words she is entering in the search box.

The search feature can further be enhanced using google type search wherein the documents where the keyword occurs 


\section{International Journal of Science and Research (IJSR) \\ ISSN (Online): 2319-7064}

Index Copernicus Value (2013): 6.14 | Impact Factor (2015): 6.391

would be displayed to the CSR. This would require inverted indexing and an efficient keyword searching mechanism. One scenario where this feature would be especially useful is searching of past trouble tickets and their resolutions. Alternatively we can utilize Google's custom search engine offering for such scenarios.

In the case of self-care, voice and video search technology would be quite useful for customers who wish to directly search ringtones, pictures and movies without calling up customer care.

\subsection{KM Workflow Management}

A successful KM needs as much of automation as possible. Need for human intervention should be kept to the minimum. Documents that are generated are not always suited for CSR use. Some of them will have to preprocessed and modified before a CSR can utilize them. Free text email communications should be complemented or if possible, replaced with structured communication. Extracting information out of emails and word documents may require use of advanced text processing algorithms. Automation helps in reducing delays that are inherent in human communication. A well-designed workflow management system needs to be in place for automating the flow of electronic documents and their approval and final use at CSR desk.

\section{Discussion}

We have seen the importance of Knowledge Management to customer care effectiveness. We started with a brief discussion of the prerequisites for KM implementation and shown what are the typical $\mathrm{KM}$ requirements from the customer care perspective. We covered the information structures and categories as applied to telecom industry. We have shown what all integrations can be done with KM portal and what all navigational improvements can be done within $\mathrm{KM}$ portal in order to reduce time taken by the CSR for accessing the relevant information, thereby improving customer satisfaction. We have also stressed on the need for KM Workflow Management for timely handling and delivery of information to CSR. positive impact on customer handling effectiveness and hence on customer satisfaction.

\section{References}

[1] Davenport, T.H. (1994). "Saving IT's Soul: Human Centered Information Management". Harvard Business Review 72 (2): 119- 131.

[2] McInerney, C. (2002). "Knowledge Management and the Dynamic Nature of Knowledge". Journal of the American Society for Information Science and Technology 53 (12): 1009-1018.

[3] Kimiz Dalkir (2011), Knowledge Management in Theory and Practice (MIT Press), Massachusetts.

[4] Stephanie B., Nick M. (2014). Designing a Successful KM Strategy: A Guide for the Knowledge Management Professional, Information Today Inc. New Jersey.

[5] Nick M., Patrick L. (2016). The Knowledge Manager's Handbook: A Step-by-Step Guide to Embedding Effective Knowledge Management in your Organization. Kogan Page. London.

[6] Chor-Beng A.L. (2008). Strategic integration of knowledge management and customer relationship management. Journal of Knowledge Management, Vol. 12 Iss: 4, pp. $131-146$.

[7] Ranjit B., Vijayan S. (2003). Application of knowledge management technology in customer relationship management. Knowledge and Process Management Volume 10, Issue 1, pages 3-17.

[8] Peter T. (2002). A taxonomy of knowledge management software tools: origins and applications. Evaluation and Program Planning. Volume 25, Issue 2, May 2002, Pages 183-190. Elsevier. London.

\section{Author Profile}

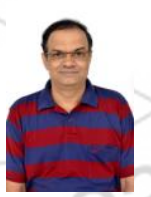

A.V. Murali received his B.Tech and M.Tech degrees in Metallurgical Engineering from IIT Madras. He has got an extensive work experience of over 25 years in diverse software application domains. His areas of work are primarily centered on applied research and systems implementation. His areas of research interest include software engineering, data mining and text mining, mathematical problem solving, gamification and game based learning.

\section{Future Scope}

While the paper focusses on the telecom domain, the same ideas can be implemented in other industries such as banking, utilities, grocery, healthcare and travel. The author intends to implement these ideas to customer care scenarios in various industries.

\section{Conclusion}

Knowledge management is one of the most vital aspects for customer care effectiveness. Data and information are available all over the organization in various forms. A proper $\mathrm{KM}$ implementation plan is required to harness them. A wellplanned KM initiative with a well-designed GUI, integrations with other systems and automated workflows can have a huge 